J Am Chem Soc. 2016 September 21; 138(37): 12069-12072. doi:10.1021/jacs.6b08486.

\title{
Catalytic Enantioselective Carbon-Oxygen Bond Formation: Phosphine-Catalyzed Synthesis of Benzylic Ethers via the Oxidation of Benzylic C-H Bonds
}

\author{
Daniel T. Ziegler and Gregory C. Fu* \\ Division of Chemistry and Chemical Engineering, California Institute of Technology, Pasadena, \\ California 91125, United States
}

\begin{abstract}
Benzylic alcohols and ethers are common subunits in bioactive molecules, as well as useful intermediates in organic chemistry. In this report, we describe a new approach to the enantioselective synthesis of benzylic ethers, through the chiral phosphine-catalyzed coupling of two readily available partners, $\gamma$-aryl-substituted alkynoates and alcohols, under mild conditions. In this process, the alkynoate partner undergoes an internal redox reaction, specifically, the benzylic position is oxidized with good enantioselectivity, and the alkyne is reduced to the alkene.
\end{abstract}

\section{Graphical Abstract}

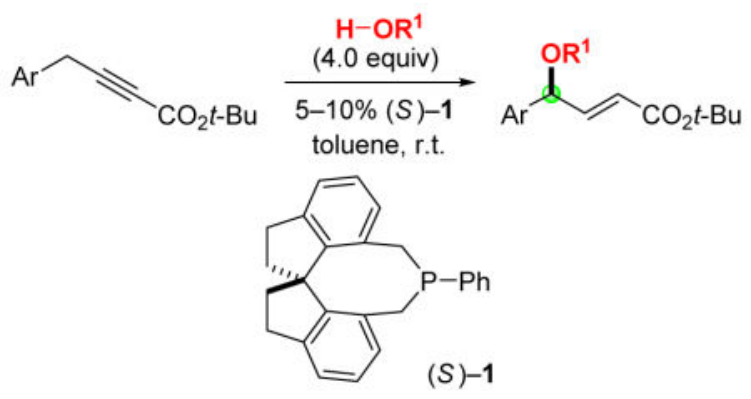

\begin{abstract}
Enantioenriched benzylic ethers are valuable targets in chemistry, both as endpoints ${ }^{1}$ and as intermediates in the synthesis of other useful families of molecules through simple deprotection, ${ }^{2}$ coupling reactions, ${ }^{3}$ and the like. A variety of strategies for the generation of chiral benzylic ethers have been described, including catalytic enantioselective processes. In the latter cases, the benzylic ether is typically produced from an enantioenriched benzylic alcohol, which is most often synthesized from a carbonyl compound via asymmetric hydrogenation or nucleophilic addition (Figure 1), ${ }^{4}$ the enantioselective oxidation of $\mathrm{C}-\mathrm{H}$ bonds provides an alternative approach to chiral benzylic alcohols. ${ }^{5}$
\end{abstract}

Corresponding Author: gcfu@caltech.edu.

The authors declare no competing financial interests.

Supporting Information

The Supporting Information is available free of charge on the ACS Publications website at DOI:

Procedures and characterization data (PDF) 
In this report, we describe a distinct, direct method for the catalytic asymmetric synthesis of benzylic ethers. Specifically, we demonstrate that, with the aid of a chiral phosphine catalyst, $\gamma$-aryl alkynoates can be coupled with alcohols to generate benzylic ethers in good enantiomeric excess under notably simple and mild conditions (eq 1); if desired, the resulting ethers can be transformed into other useful compounds through functionalization of the olefin or conversion to a benzylic alcohol.

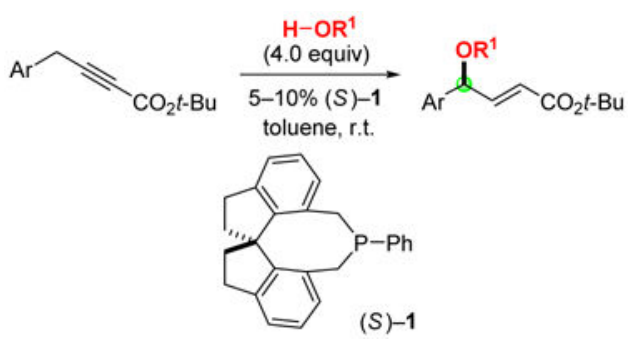

We have recently reported that chiral phosphines can catalyze the enantioselective intermolecular coupling of an array of carbon, nitrogen, and sulfur nucleophiles with the $\gamma$ position of allenoates and related compounds (Figure 2), ${ }^{6,7,8}$ furthermore, corresponding intramolecular reactions of nitrogen and oxygen nucleophiles can furnish enantioenriched heterocycles. ${ }^{6 e, 9}$ More recently, through the use of a bifunctional phosphine catalyst, Jacobsen has also achieved asymmetric intermolecular couplings of nitrogen nucleophiles. ${ }^{10}$ With respect to even a racemic variant of the coupling illustrated in Figure 2, to the best of our knowledge, there are no reports of phosphine-catalyzed $\gamma$ additions of any nucleophiles to alkynoates/allenoates that bear an aryl group in the $\gamma$ position, ${ }^{11}$ and there is only a single example of an intermolecular coupling of an oxygen nucleophile with any $\boldsymbol{\gamma}$-substituted alkynoate/allenoate. ${ }^{12}$

We were therefore pleasantly surprised to determine that, under the simple conditions presented in Table 1, commercially available spirophosphine $\mathbf{1}^{6 \mathrm{e}, 9,13}$ catalyzes the coupling of an alcohol with an alkynoate that is substituted with a phenyl group in the $\gamma$ position, furnishing the desired benzylic ether with very good enantioselectivity and in high yield (97\% ee, $94 \%$ yield; entry 1). This internal redox process oxidizes the benzylic carbon while reducing the alkyne. Use of the corresponding allenoate leads to essentially the same ee, although the yield is slightly lower (88\%; entry 2). Phosphepine 2, which has served as an effective catalyst for other couplings, ${ }^{6 b, f}$ provides the desired benzylic ether with diminished efficiency (62\% ee, $74 \%$ yield; entry 3). Use of a lower catalyst loading or less of the alcohol has no impact on enantioselectivity, but results in a minor erosion in yield (80-89\%; entries 4-6). Similarly, the ee of the coupling is unaffected by the presence of a small amount of water, although the yield is modestly lower (84\%; entry 7).

We next examined the scope of this new transformation with regard to the aryl substituent of the alkynoate; these substrates are readily accessible via the coupling of benzylic chlorides with $t$-butyl propiolate. ${ }^{14} \mathrm{We}$ have established that this phosphine-catalyzed asymmetric 
synthesis of benzylic ethers proceeds with good enantioselectivity with a wide array of aryl groups, furnishing the desired products under straightforward and mild conditions (Table 2). For example, the aromatic substituent can be electron-rich or electron-poor (entries 2 and 3), and it can be ortho-substituted, although in such cases a higher catalyst loading is required in order to obtain good yields (10\% catalyst; entries 4 and 5). Furthermore, the aryl group can be an extended $\pi$-system (entries 6 and 7 ) and it can be a sulfur or a nitrogen heterocycle (entries $8-10)$. On a gram scale (1.40 g of product), the coupling depicted in entry 2 proceeds in $94 \%$ ee and $91 \%$ yield. $^{15}$

The scope with respect to the electrophile is not limited to aryl- and ester-substituted compounds of the type depicted in Table 2. For example, substrates that bear an amide, rather than an ester, group (eq 2), as well as a methyl, rather than an aryl, substituent (eq 3), can be employed. ${ }^{16}$ In both cases, the desired coupling product is generated with high enantioselectivity and in very good yield.
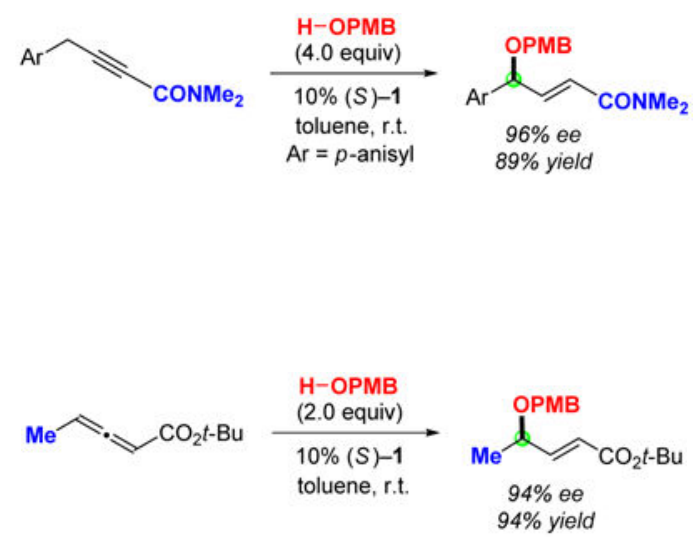

A variety of primary alcohols can be employed as the nucleophilic coupling partner (Table 3). For example, benzyl alcohol as well as an electron-poor benzylic alcohol are suitable substrates, furnishing ee's and yields that are similar to those observed for $p$-methoxybenzyl alcohol (entries 1-3). Other functionalized, as well as unfunctionalized, alcohols also afford the desired benzylic ether with very good enantioselectivity (entries 4-10). The efficiency of $\mathrm{C}-\mathrm{O}$ bond formation is sensitive to the steric demand of the nucleophile: although coupling proceeds in fairly good yield with a $\beta$-branched primary alcohol (entry 10), cyclohexanol is not a useful partner under our standard conditions ( $<20 \%$ yield). An initial attempt to employ water as the nucleophile was not successful.

Although saturated secondary alcohols such as cyclohexanol are not effective coupling partners under our standard conditions, during our study of the use of primary alcohols as nucleophiles (Table 3), we observed that unsaturated alcohols such as benzyl alcohol and allyl alcohol are significantly more reactive than saturated alcohols (eq 4). This enhanced reactivity enables the application of our phosphine-catalyzed asymmetric coupling to a benzylic secondary alcohol, 1-phenylethanol (eq 5 and eq 6). By examining the 
stereochemical outcome for the reaction of each enantiomer of this chiral alcohol, catalyzed by $(S)-\mathbf{1}$, we can determine whether the stereochemistry of the new benzylic stereocenter is primarily controlled by the stereochemistry of the alcohol or that of the phosphine catalyst. Because different diastereomers of the benzylic ether are favored in these two couplings (both reactions proceed with $>20: 1 \mathrm{dr}$ ), we conclude that the stereochemical course is catalyst-controlled. ${ }^{17}$
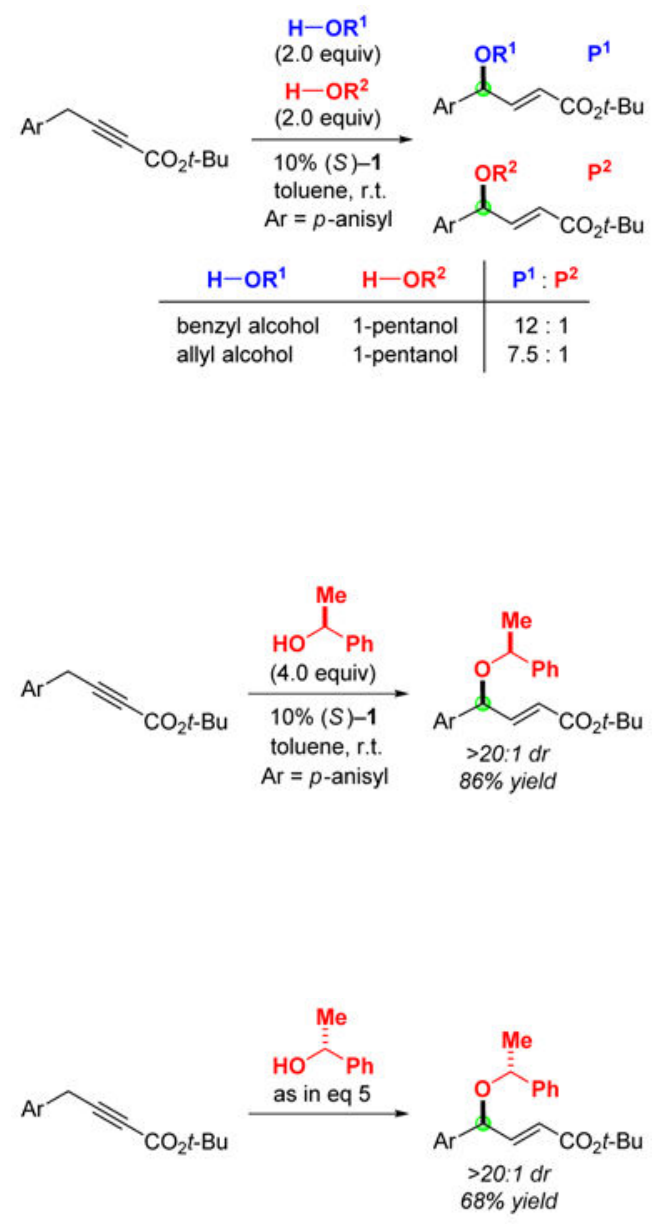

The enantioenriched benzylic ethers that are produced in these phosphine-catalyzed asymmetric couplings bear an olefin that can be further functionalized. For example, conjugate addition and dihydroxylation proceed with good diastereoselectivity and in good yield (eq 7 and eq 8); the diol generated via dihydroxylation is related to an intermediate employed in the total synthesis of (+)-crassalactone A. ${ }^{18}$ If the enantioenriched benzylic alcohol, rather than the ether, is the target, then deprotection can be achieved in good yield (eq 9). 

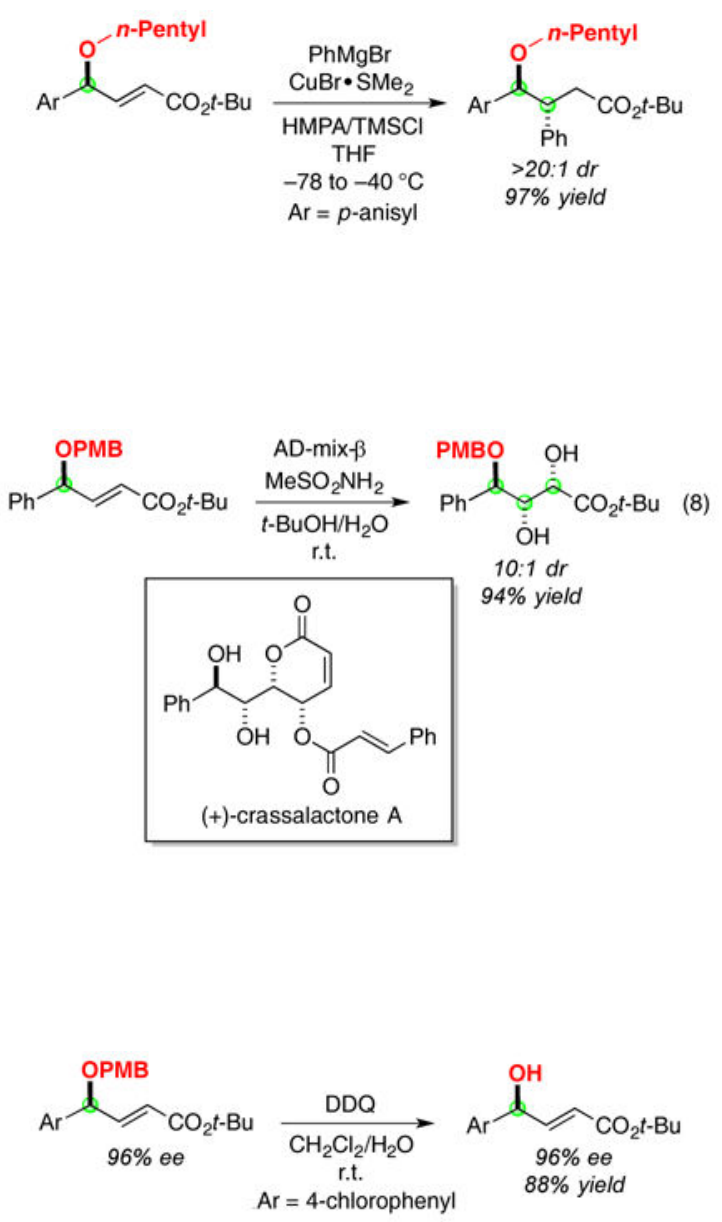

A possible mechanism for this method for the catalytic asymmetric synthesis of benzylic ethers is outlined in Figure 3. ${ }^{7}$ Nucleophilic addition of the phosphine to the $\beta$ position of the alkynoate generates a zwitterion (A) that tautomerizes to form new zwitterion $\mathbf{B}$. Intermediate $\mathbf{B}$ deprotonates the alcohol ( $\mathrm{ROH})$ to afford an ion pair $(\mathbf{C})$. The alkoxide then adds to the electrophilic $\gamma$ carbon, producing ylide $\mathbf{D}$. Tautomerization furnishes zwitterion $\mathbf{E}$, which eliminates the phosphine to regenerate the catalyst and yield the product.

For the enantioselective coupling illustrated in entry 2 of Table 2, we have determined through ${ }^{31} \mathrm{P}$ NMR spectroscopy that the free phosphine (1) is the resting state of the catalyst during the reaction. In addition, through ${ }^{1} \mathrm{H}$ NMR spectroscopy, we have discovered that the alkynoate isomerizes to the allenoate to a significant extent during the coupling, presumably via elimination of the phosphine from intermediate A (Figure 3).

In summary, commercially available chiral phosphine $\mathbf{1}$ serves as an effective catalyst for the enantioselective coupling of alcohols with $\gamma$-aryl alkynoates, thereby directly generating benzylic ethers in good ee from readily available starting materials under simple and mild 
conditions. Although related asymmetric phosphine-catalyzed intermolecular couplings have been reported, no success has been described with an electrophile that bears an aryl substituent in the $\gamma$ position or with an oxygen nucleophile. A wide range of aromatic groups (including heterocycles) and a broad array of primary alcohols are compatible with this new process. The resulting enantioenriched benzylic ethers can be useful both as endpoints and as intermediates in organic chemistry. Further investigations of the use of phosphines as chiral nucleophilic catalysts are underway.

\section{Supplementary Material}

Refer to Web version on PubMed Central for supplementary material.

\section{Acknowledgments}

Support has been provided by the National Institutes of Health (National Institute of General Medical Sciences: R01-GM57034). We thank William Reichard, Jun Myun Ahn (X-ray crystallography), and Dr. Michael K. Takase (X-ray crystallography) for assistance.

\section{References}

1. For a recent example, see: Takano R, Yoshida M, Inoue M, Honda T, Nakashima R, Matsumoto K, Yano T, Ogata T, Watanabe N, Hirouchi M, Kimura T, Toda N. Bioorg Med Chem. 2015; 23:55465565. See also omarigliptin and Strattera ${ }^{\mathrm{TM}}$. [PubMed: 26234904]

2. Many benzylic alcohols are bioactive, including epinephrine and Zetia ${ }^{\mathrm{TM}}$.

3. For representative examples and leading references, see: Tollefson EJ, Hanna LE, Jarvo ER. Acc Chem Res. 2015; 48:2344-2353. [PubMed: 26197033] Harris MR, Konev MO, Jarvo ER. J Am Chem Soc. 2014; 136:7825-7828. [PubMed: 24852707]

4. For some leading references on the catalytic asymmetric hydrogenation of ketones, see: Asymmetric Catalysis on Industrial Scale. Blaser H-U, Federsel H-J. Wiley-VCHWeinheim2010For a discussion of the catalytic enantioselective alkylation of aldehydes, see: Santanilla AB, Leighton JL. Science of Synthesis, Stereoselective Synthesis. De Vries JG, Molander GA, Evans PA. Georg Thieme VerlagStuttgart2011; 2:401-447.

5. For a discussion and leading references, see: Andrus MB. Science of Synthesis, Stereoselective Synthesis. De Vries JG, Molander GA, Evans PA. Georg Thieme VerlagStuttgart2011; 3:469-482.

6. Carbon nucleophile: Smith S, Fu GC. J Am Chem Soc. 2009; 131:14231-14233. [PubMed: 19772285] Carbon nucleophile: Sinisi R, Sun J, Fu GC. Proc Natl Acad Sci USA. 2010; 107:20652-20654. [PubMed: 20624987] Sulfur nucleophile: Sun J, Fu GC. J Am Chem Soc. 2010; 132:4568-4569. [PubMed: 20222657] Sulfur nucleophile: Fujiwara Y, Sun J, Fu GC. Chem Sci. 2011; 2:2196-2198. [PubMed: 22216403] Nitrogen nucleophile: Lundgren RJ, Wilsily A, Marion N, Ma C, Chung YK, Fu GC. Angew Chem Int Ed. 2013; 52:2525-2528.Carbon nucleophile: Kalek M, Fu GC. J Am Chem Soc. 2015; 137:9438-9422. [PubMed: 26192217]

7. For pioneering studies of non-enantioselective processes (no $\gamma$ substituent), see: Trost BM, Li CJ. J Am Chem Soc. 1994; 116:3167-3168.Zhang C, Lu X. Synlett. 1995:645-646.

8. For the initial investigation of asymmetric catalysis wherein the stereochemistry at the $\delta$ (not the $\gamma$ ) position of the product is controlled, see: Chen Z, Zhu G, Jiang Q, Xiao D, Cao P, Zhang X. J Org Chem. 1998; 63:5631-5635.

9. Chung YK, Fu GC. Angew Chem Int Ed. 2009; 48:2225-2227.

10. Nitrogen nucleophile: Fang Y-Q, Tadross PM, Jacobsen EN. J Am Chem Soc. 2014; 136:1796617968. [PubMed: 25496451]

11. For examples of failed attempts, see: (a) Footnote 12 in Ref. 6f. (b) Entry 5 of Table 3 in: Zhou QF, Zhang K, Kwon O. Tetrahedron Lett. 2015; 56:3273-3276. [PubMed: 26041942]

12. See eq 2 in: Trost BM, Li C-J. J Am Chem Soc. 1994; 116:10819-10820. 
13. Xie JH, Zhou QL. Acc Chem Res. 2008; 41:581-593. [PubMed: 18311931]

14. Davies KA, Abel RC, Wulff JE. J Org Chem. 2009; 74:3997-4000. [PubMed: 19422268]

15. Phosphine catalyst $\mathbf{1}$ was recovered in $87 \%$ yield as the corresponding phosphine oxide after deliberate oxidation with $t \mathrm{BuOOH}$.

16. Under our standard conditions, if the alkyl substituent in the $\gamma$ position is larger than a methyl group, good ee but modest yield is observed.

17. When racemic 1-phenylethanol is employed as the nucleophile, a very modest kinetic resolution is observed $(s=2.2)$.

18. Shekhar V, Reddy DK, Suresh V, Babu DC, Venkateswarlu Y. Tetrahedron Lett. 2010; 51:946-948.

J Am Chem Soc. Author manuscript; available in PMC 2017 September 21. 
<smiles>[R]C(=O)[Al]</smiles>

$\mathrm{H}_{2} \downarrow$

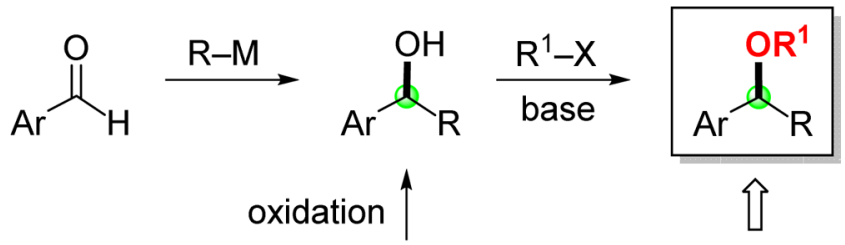

Examples of uses:

- bioactive target molecules

- protected benzylic alcohols

- substrates for enantioselective couplings

Figure 1.

Enantioenriched benzylic ethers: Common catalytic asymmetric methods for their synthesis via benzylic alcohols; examples of their significance. 


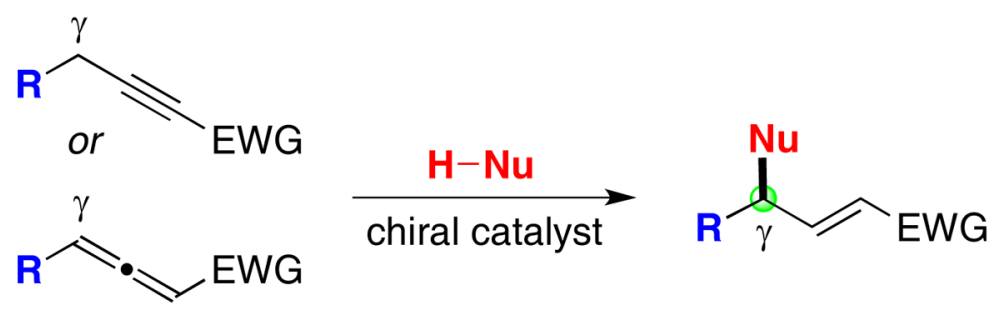

\begin{tabular}{|cc|}
\hline $\mathbf{R}$ & $\mathrm{Nu}$ \\
\hline alkyl & $\begin{array}{c}\text { carbon, nitrogen, and sulfur nucleophiles } \\
\text { (intermolecular couplings) } \\
\text { nitrogen and oxygen nucleophiles } \\
\text { (intramolecular couplings) }\end{array}$ \\
aryl & no reports \\
\hline
\end{tabular}

Figure 2.

Reports to date of phosphine-catalyzed enantioselective $\gamma$ additions $(\mathrm{R} \neq \mathrm{H})$. 


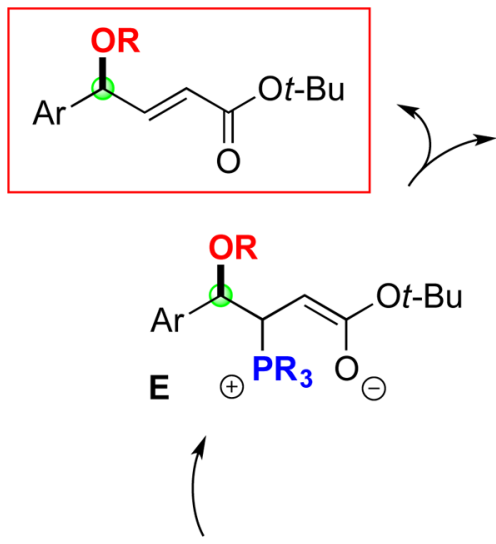<smiles>[R5]CCCCCCC#CC(=O)OCC</smiles>

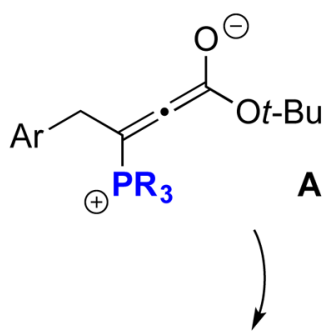<smiles>[R16]OC(=O)CC([R6])C([Al])O[R7]</smiles><smiles>[R5]OC(=CC(=O)O)OCCBr</smiles><smiles>C1CCCC1</smiles><smiles>[CH-]1CC[Co]1</smiles><smiles>[R5]C(CC(=O)OCC)=C([3H])[3H]</smiles>

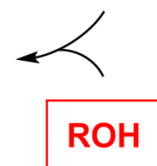

Figure 3.

Outline of a possible pathway for the phosphine-catalyzed asymmetric synthesis of benzylic ethers. For the sake of simplicity, all steps are drawn as irreversible, and all alkenes are illustrated as single isomers. 


\section{Table 1}

Phosphine-Catalyzed Asymmetric Synthesis of Benzylic Ethers: Effect of Reaction Parameters ${ }^{a}$

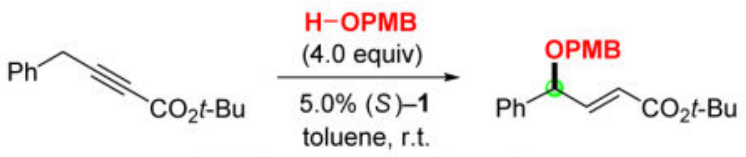

$\mathrm{PMB}=$ para-methoxybenzyl

"standard conditions"

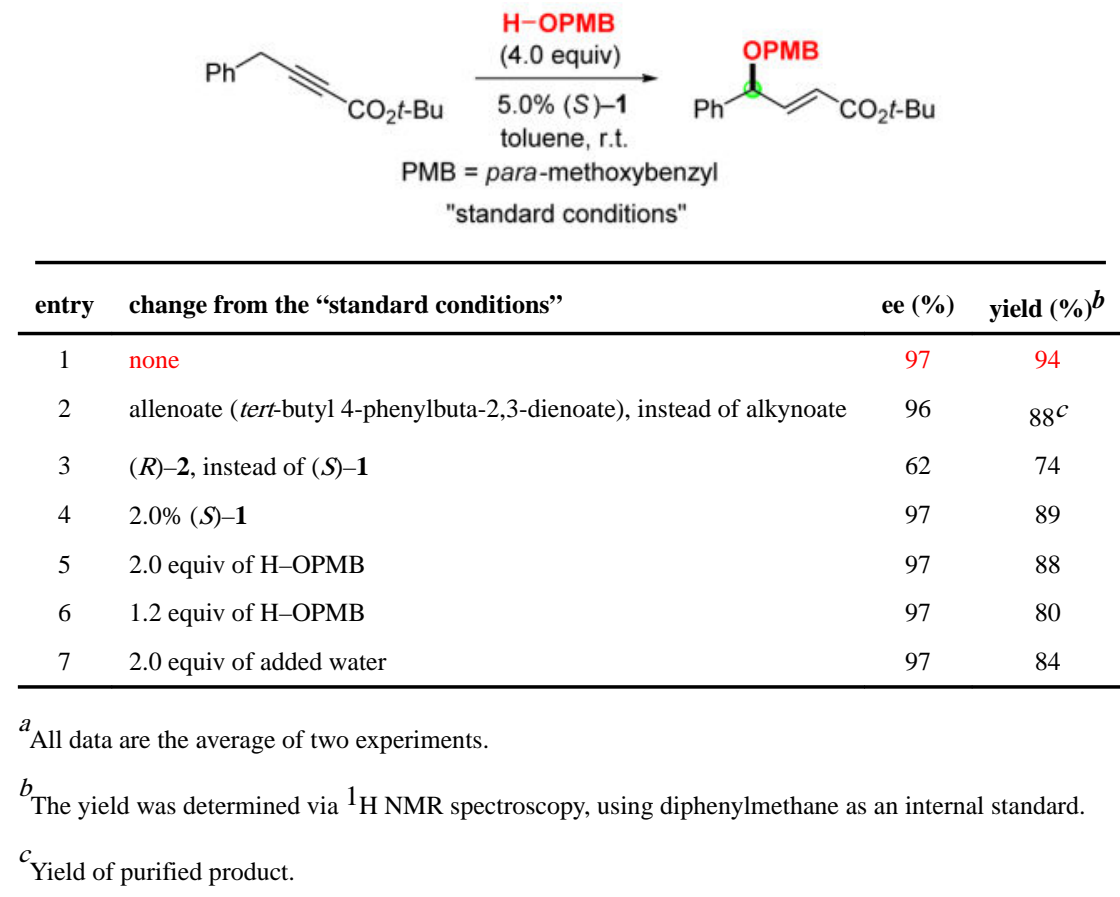

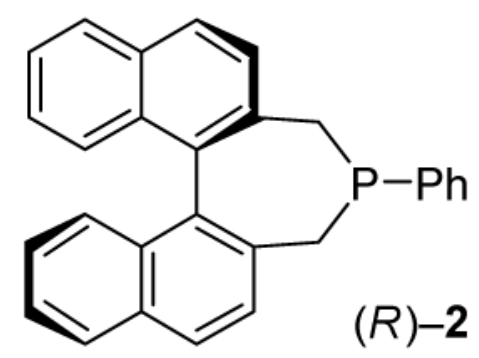




\section{Table 2}

Phosphine-Catalyzed Asymmetric Synthesis of Benzylic Ethers: Scope with Respect to the Aryl Group ${ }^{a}$

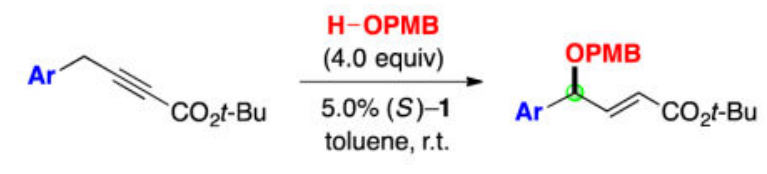

\begin{tabular}{cccc}
\hline entry & ee (\%) & yield (\%) \\
\hline 1 & 96 & 96 \\
\hline
\end{tabular}

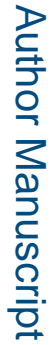

$5^{c}$<smiles>Cc1cccc2ccccc12</smiles>

7<smiles>Cc1ccc2ccccc2c1</smiles>

8<smiles>[Z6]c1cccs1</smiles>

9<smiles>[Y6]c1ccsc1</smiles>

92

96

10<smiles>Cc1ccc2c(ccn2S)c1</smiles>

\footnotetext{
${ }^{a}$ All data are the average of two experiments.

$b_{\text {Yield of purified, isolated product. }}$

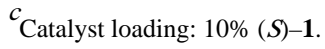

${ }^{d}$ Amount of nucleophile: 2.0 equiv.
} 
Table 3

Phosphine-Catalyzed Asymmetric Synthesis of Benzylic Ethers: Scope with Respect to the Alcohol $^{a}$

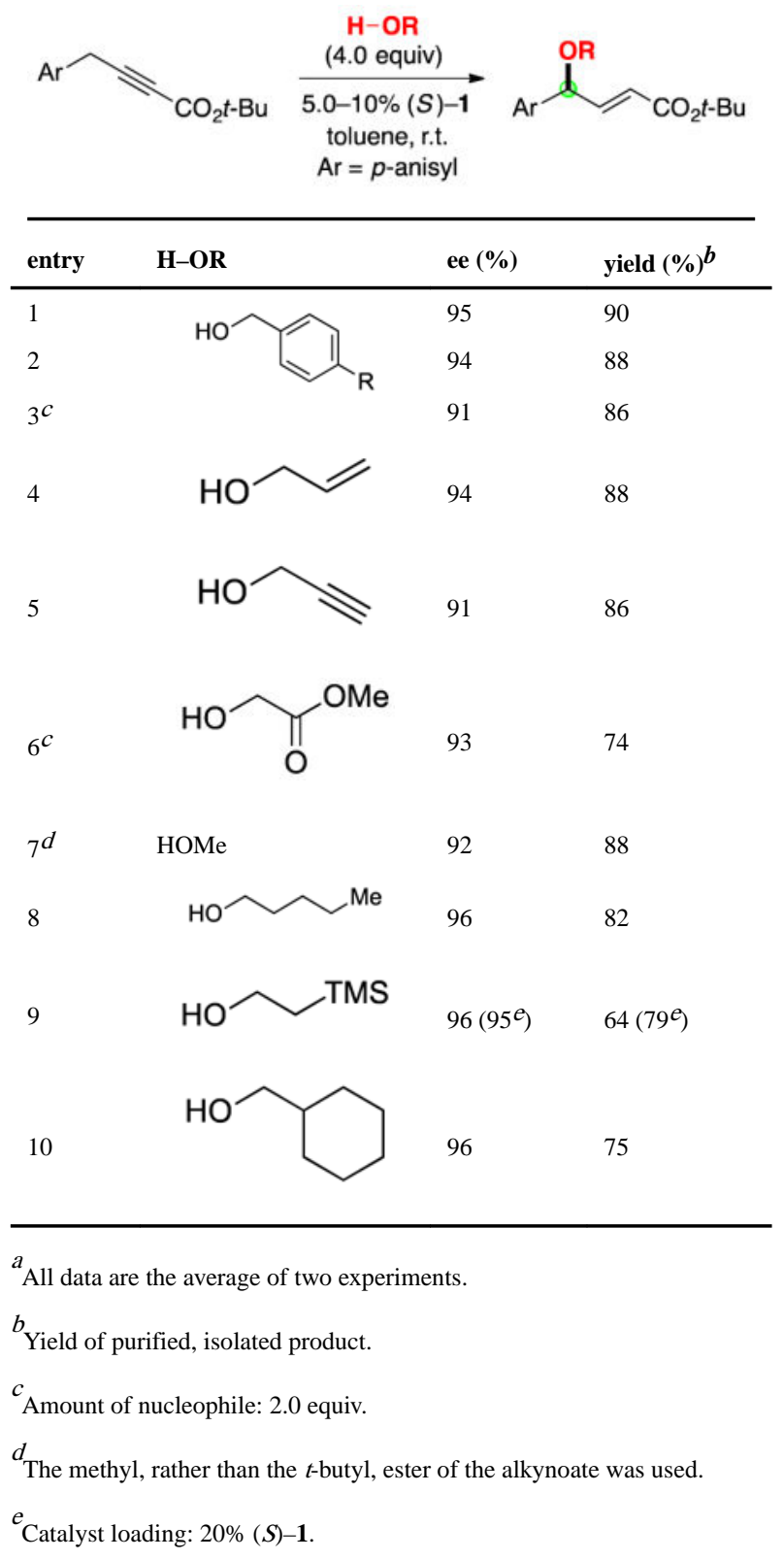

J Am Chem Soc. Author manuscript; available in PMC 2017 September 21. 